\title{
A study on relationship between quality of life and employee performance
}

\author{
Marziyeh Pourbagher $^{a^{*}}$, Ali Akbar Bani ${ }^{\mathrm{b}}$, Mehdi Salehi ${ }^{\mathrm{b}}$, Somayyeh $\operatorname{Iri}^{\mathrm{b}}$ and Saeid Sedaghat ${ }^{\mathrm{a}}$
}

${ }^{a}$ Department of Accounting, Damghan Branch, Islamic Azad University, Damghan, Iran

${ }^{b}$ Department of Mathematics, Islamic Azad university, Gorgan branch, Gomishan center, Gomishan, Iran

\section{H R O N I C L E}

Article history:

Received January 20, 2014

Accepted 5 July 2014

Available online

July 142014

Keywords:

Quality of life

Job Performance

Sport

\section{A B S T R A C T}

This paper studies the relationship between quality of life and its eight components with employee performance in general directorate of youth and sport in province of Golestan, Iran. The study uses a questionnaire developed by Walton (1974) [Walton, R. E. (1974). Improving quality of work life. Harvard Business Review, 52(3), 12.] for quality of life and a standard questionnaire named ACHIEVE consists of 25 questions for measuring the performance. Using Spearman correlation test, the study has determined a positive and meaningful relationship between employee performance and eight components of Walton's model including adequate and fair compensation, safe and healthy working conditions, development of human competencies, growth and security, social integration, constitutionalization and total life space and social reliance.

\section{Introduction}

During the past few years, there have been tremendous efforts to learn how to improve job performance through improving quality of life. Aziz et al. (2011) for instance, studied the relationship between work and non-work variables and quality of work life. They reported that both work variables and non-work variables would matter in detecting the quality of work life. Shahbazi et al. (2011) performed a survey on relationship between the quality of work life and performance of Department Chairpersons of Esfahan University and Esfahan Medical Science University and reported that developing human capabilities, constitutionalism in the work organization, total life space and social integration in the work organization could forecast employee performance. Sirisawasd et al. (2014) stated that the quality of worklife would not fully examine every factor related to worklife in all cultures. They translated the Work-related Quality of Life Scale-2 (WRQLS2) into Thai, to evaluate the validity and reliability of the Thai-translated version, and to study the tool's accuracy vis-à-vis nursing in Thailand. They concluded that the Thai version of a WRQLS

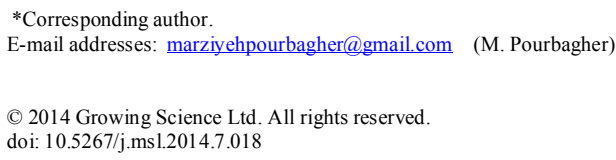


appeared to be well validated and practicable for detecting the quality of the work-life among nurses in Thailand. Gillet et al. (2013) examined two possible psychological techniques, which link transformational leadership behaviors to nurses' quality of work life. They also investigated the relationship between nurses' quality of work life and their work engagement. They reported that distributive justice and interactional justice could fully mediate the relationship between transformational leadership and nurses' quality of work life. They also reported that nurses' quality of work life was positively associated with their work engagement.

Lin et al. (2013a) explored how leisure benefit systems could influence on frontline employees' quality of life while they face work-to-leisure conflicts. This study applied leisure benefit system satisfaction as a moderator between work-to-leisure conflict and quality of life, based on a model and a cross-industry survey of some frontline hospitality employees in hotel/resort, tourist attraction, and airline industries. They reported that work-to-leisure conflict was negatively associated with quality of life, leisure benefit system satisfaction was positively associated quality of life, and the direct impact of leisure benefit system satisfaction on leisure satisfaction was bigger than it is on job satisfaction. When a frontline employee was highly satisfied with a leisure benefit system, leisure benefit system satisfaction was detected to exert a moderating impact between work-to-leisure conflict and quality of life. They also reported that a leisure benefit system was a coping resource for frontline employees' work-to-leisure conflict. Lin et al. (2013b), in other work, studied psychometric properties of the Chinese version of the Work-Related Quality of Life Scale-2 in the nursing profession.

\section{The proposed model}

This paper studies the relationship between quality of life and its eight components with employee performance in general directorate of youth and sport in province of Golestan, Iran. The study uses a questionnaire developed by Walton (1974) for quality of life and a standard questionnaire named ACHIEVE consists of 25 questions for measuring the performance. The main hypothesis of this survey is as follows,

Main hypothesis: There is a positive and meaningful relationship between quality of life and employee performance.

There are eight sub-hypotheses associated with the proposed study of this paper as follows,

1. There is a meaningful relationship between adequate and fair compensation and employee performance.

2. There is a meaningful relationship between social integration and employee performance.

3. There is a meaningful relationship between safe and healthy working conditions and employee performance.

4. There is a meaningful relationship between growth and security and employee performance.

5. There is a meaningful relationship between constitutionalization and employee performance.

6. There is a meaningful relationship between total life space and employee performance.

7. There is a meaningful relationship between development of human competencies and employee performance.

8. There is a meaningful relationship between social reliance and employee performance. 
The population of the survey includes all 80 employees of general directorate of youth and sport in province of Golestan, Iran. In our survey, $67.5 \%$ of the participants were female and $32.5 \%$ of them were male. Fig. 1 demonstrates the summary of other personal characteristics of the participants.

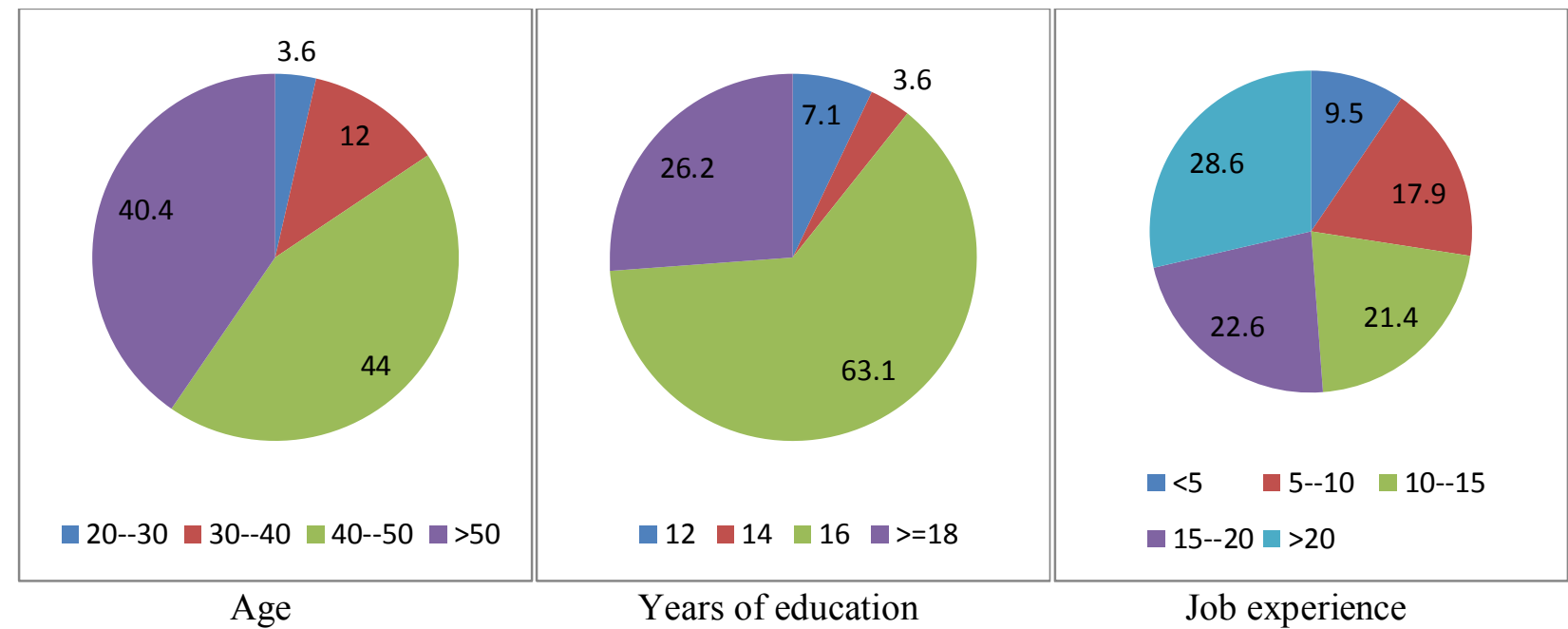

Fig. 1. Personal characteristics of the participants

As we can observe from the results of Fig. 1, most of the participants were middle-aged people with good educational background and good job experiences. In order to examine the main hypothesis as well as sub-hypotheses of the survey, we have use Kolmogorov-Smirnove test and the results have indicated that the data were not normally distributed. Therefore, we use Spearman correlation test to do the survey.

\section{The results}

In this section, we present details of our findings on testing the main hypothesis as well as all eight hypotheses of the survey. Table 1 summarizes the results of the implementation of Spearman correlation test.

Table 1

The summary of Spearman correlation test

\begin{tabular}{clcccc}
\hline Hyp. & Variable & $\begin{array}{c}\text { Spearman } \\
\text { ratio }\end{array}$ & P-value & Critical value & Result \\
\hline Main & Quality of life & 0.748 & 0 & 1.96 & Confirmed \\
1 & adequate and fair compensation & 0.814 & 0 & 1.96 & Confirmed \\
2 & social integration & 0.557 & 0.022 & 1.96 & Confirmed \\
3 & safe and healthy working conditions & 0.628 & 0.01 & 1.96 & Confirmed \\
4 & growth and security & 0.609 & 0.014 & 1.96 & Confirmed \\
5 & constitutionalization & 0.806 & 0 & 1.96 & Confirmed \\
6 & total life space & 0.791 & 0 & 1.96 & Confirmed \\
7 & development of human competencies & 0.541 & 0.041 & 1.96 & Confirmed \\
8 & social reliance & 0.572 & 0.003 & 1.96 & Confirmed \\
\hline
\end{tabular}

As we can observe from the results of Table 1, there are some positive meaningful relationship between different components of quality of life and employee performance. 


\section{Discussion and conclusion}

Based on the results of survey, quality of life influences positively on job performance. Among eight components of quality of life, Adequate and fair compensation is the most important factor followed by constitutionalization, total life space. The results of our survey are consistent with other findings in the literature. The results of this study are consistent with findings reported earlier by Lin et al. (2013a, 2013b) and Gillet et al. (2013).

\section{Acknowledgement}

The authors would like to thank the anonymous referees for constructive comments on earlier version of this paper.

\section{References}

Aziz, R. A., Nadzar, F. M., Husaini, H., Maarof, A., Radzi, S. M., \& Ismail, I. (2011). Quality of work life of librarians in government academic libraries in the Klang Valley, Malaysia. The International Information \& Library Review, 43(3), 149-158.

Gillet, N., Fouquereau, E., Bonnaud-Antignac, A., Mokounkolo, R., \& Colombat, P. (2013). The mediating role of organizational justice in the relationship between transformational leadership and nurses' quality of work life: A cross-sectional questionnaire survey. International journal of nursing studies, 50(10), 1359-1367.

Lin, J. H., Wong, J. Y., \& Ho, C. H. (2013a). Promoting frontline employees' quality of life: Leisure benefit systems and work-to-leisure conflicts. Tourism Management, 36, 178-187.

Lin, S., Chaiear, N., Khiewyoo, J., Wu, B., \& Johns, N. P. (2013b). Preliminary psychometric properties of the chinese version of the Work-Related Quality of Life Scale-2 in the nursing profession. Safety and Health at Work, 4(1), 37.

Shahbazi, B., Shokrzadeh, S., Bejani, H., Malekinia, E., \& Ghoroneh, D. (2011). A survey of relationship between the quality of work life and performance of Department Chairpersons of Esfahan University and Esfahan Medical Science University. Procedia-Social and Behavioral Sciences, 30, 1555-1560.

Sirisawasd, P., Chaiear, N., Johns, N. P., \& Khiewyoo, J. (2014). Validation of the Thai Version of a Work-related Quality of Life Scale in the Nursing Profession. Safety and Health at Work, 5(2), 8085.

Walton, R. E. (1974). Improving quality of work life. Harvard Business Review, 52(3), 12. 